\title{
A modelagem computacional na educação infantil: teorização e possibilidade de implementação pedagógica
}

\author{
The computational modeling in early childhood education: theorization and the \\ possibility of pedagogical implementation
}

\author{
Nájela Tavares Ujiie \\ najelaujiie@yahoo.com.br \\ Sandra Regina Gardacho Pietrobon \\ spietrobom@gmail.com \\ Antonio Carlos Frasson \\ acfrasson@utfpr.edu.br \\ Nilceia Aparecida Maciel Pinheiro \\ nilceia@utfpr.edu.br \\ Sani de Carvalho Rutz da Silva \\ sanirutz@gmail.com
}

\begin{abstract}
Resumo
O artigo apresentado configura-se por um ensaio teórico voltado à prática de ensino, o qual tem como objetivo discutir a temática da modelagem computacional, promovendo aproximação com a educação infantil. Nesse sentido, para além da discussão teórica do conceito da modelagem computacional e sua aplicação, de educação infantil e suas nuances pedagógicas, cria-se no delineamento deste texto ensaio, uma seara tridimensional de manipulação e provocação, sustentada pela argumentação discursiva, visando à consumação dos preceitos alinhados, na convergência da modelagem computacional aplicada ao trabalho pedagógico com a pequena infância. Tem-se a aproximação materializada via a exploração do Banco Internacional de Objetos Educacionais, do Ministério da Educação (MEC), a partir do software "Blocs Lógics" de Alonso, o qual traz à tona a exemplificação, partindo da área da matemática na educação infantil e dos conteúdos geométricos, tendo os blocos lógicos como objeto de modelagem didático-pedagógico. Assim, a discussão fomentada leva a concluir que existe pertinência na associação da modelagem computacional ao trabalho pedagógico com crianças da faixa etária de 4 a 6 anos, como fonte importante de criação, construção do conhecimento e letramento matemático.
\end{abstract}

Palavras-chave: Modelagem computacional; Educação infantil; Prática pedagógica.

\begin{abstract}
The paper presented is configured by a theoretical about teaching practice, which aims to discuss the topic of computer modeling, promoting approach to early childhood education. In this sense, besides the theoretical discussion of the concept of computational modeling and implementation of early childhood education and its pedagogical nuances, it creates the design of this paper test, a three-dimensional ground manipulation and provocation, supported by discursive reasoning, aiming at consummation the aligned principles, convergence of computer modeling applied to work with early childhood. It has been the approach materialized by the exploration of the International Bank of Educational Objects, the Ministry of Education (MEC), from the logical blocks software by Alonso, which raises the exemplification, starting from the area of mathematics in early childhood education and geometric content, with the logical blocks as the object of didactic and pedagogical modeling and technology as educational support aimed at early childhood plausibly. Thus fostered discussion leads to the conclusion that there is relevance in association computational modeling to the pedagogical work with children aged 4-6 years as a major source of creation, construction of knowledge and mathematical literacy.
\end{abstract}

Key-words: Computational modeling; Childhood education; Pedagogical practice. 


\section{Introdução}

No contexto brasileiro contemporâneo quando se pensa em Educação Infantil, as transformações científicas e tecnológicas que ocorreram de forma acelerada, no final do século XX e início do século XXI, se impõem delineando uma nova configuração legal expressa pela Constituição Federal (BRASIL, 1988), pela Lei de Diretrizes e Bases da Educação Nacional 9394 (BRASIL, 1996) e pelas Diretrizes Curriculares Nacionais para Educação Infantil (BRASIL, 1998, 2009). Tem-se uma compreensão de Educação Infantil que congrega o binômio cuidado-educação, a tríade brincar, criar e aprender e um norteamento curricular que deve priorizar experiências, saberes e conhecimentos constituindo aprofundamento no que converge ao patrimônio cultural, artístico, ambiental, científico e tecnológico, com afinco de promover a formação integral da criança.

A Educação Infantil como primeira etapa da Educação Básica é um tempo-espaço de formação em plenitude, voltada às crianças da primeira infância, as quais são concebidas pelas teorias e políticas educacionais vigentes sujeitos de direito. Por essa via, a educação, que se pretende plena, está compromissada com as novas demandas e exigências educacionais, dentre elas, a utilização das Tecnologias da Informação e Comunicação (TIC), o computador, a informática, os softwares associados ao processo de ensino-aprendizagem e até mesmo a modelagem computacional, enquanto importante recurso didático-pedagógico.

Pode-se salientar que projetos interligados às TIC são interativos e salutares, pois propiciam um salto qualitativo na construção cognitiva da criança através da liberdade de expressão, autonomia, criatividade, imaginação, levantamento de hipóteses e criação, obviamente, uma vez que, estejam articulados ao planejamento do professor e à intencionalidade pedagógica condizente ao nível de ensino em que atua. Uma construção contínua aliada às novas tecnologias que disponibilizam e ampliam horizontes favorecendo "a criação de experiências de aprendizagem com sentido e, ao tê-la, o estudante, os professores e os membros da comunidade se envolvem apaixonadamente no processo de aprender". (HERNÁNDEZ, 2006, p. 43).

$\mathrm{O}$ envolvimento que o teórico supracitado destaca poderá focalizar a criatividade e a inventividade, a integração social e pessoal dos estudantes, a ação associada de tecnologia e sociedade como eixos de uma proposta educativa em permanente construção e transformação. Ação educativa apaixonada e com foco no aprender, que os autores creem que pode ser 
transposta a este nível de ensino com pertinência e contribuição significativa à formação infantil.

Entretanto, é válido ressaltar que as ideias, discussões e reflexões presentes neste artigo ganham materialidade no decurso da disciplina de Fundamentos de Tecnologias Digitais para o Ensino da Ciência, do Programa de Pós-Graduação em Ensino de Ciências e Tecnologia (PPGECT) em nível de Doutorado, da Universidade Tecnológica Federal do Paraná (UTFPR), Campus de Ponta Grossa. Ao fomentar debates e questionamentos, tais como: O que é ciência? O que é conhecimento científico? O que é tecnologia? É possível implementar ações pedagógicas com a tecnologia em salas de aula da Educação Básica ao Ensino Superior? O que é modelo, modelagem e simulação? De que forma introduzir modelos interdisciplinares em sala de aula? Que relações podem ser realizadas entre os modelos construídos por alunos e o conhecimento? O que é modelagem computacional? Quais os elementos básicos necessários para a modelagem computacional? Como motivar uso da modelagem computacional na escola da Educação Básica sem que esta faça parte do currículo oficial? Quais espaços e tempos de uso da modelagem computacional? Como os alunos podem utilizar o ambiente de modelagem para apreensão do conhecimento? É possível o uso da modelagem computacional na Educação Infantil?

No decurso do caminho foram diversos os questionamentos e embates discursivos e, com intuito de dar corpus ao artigo elegeu-se o último, primando-se por investigar: Quais são as aplicações da modelagem computacional na Educação Infantil? Para cumprir com o intento, realizou-se uma busca no portal de periódicos e na base de dados de dissertações e teses da Coordenação de Aperfeiçoamento de Pessoal de Nível Superior (CAPES), no Google Acadêmico e na Scientific Electronic Library Online (SciELO), entretanto não se visualizou nenhuma incidência cruzada entre modelagem computacional e a educação infantil. Mas, a compreensão acurada da área da educação infantil leva a crer na possibilidade, o que originou o texto apresentado que ganha contorno metodológico de um ensaio teórico, o qual se respalda na compreensão de que:

O ensaio é um meio de análise e elucubrações em relação ao objeto, independentemente de sua natureza ou característica. A forma ensaística é a forma como são incubados novos conhecimentos, até mesmo científicos ou pré-científicos. [...] O ensaio não requer um sistema ou modelo específico, pois seu princípio está nas reflexões em relação aos próprios sistemas ou modelos. [...] A característica mais elementar do ensaio é a originalidade. $\mathrm{O}$ entendimento deste está relacionado à concepção de novidade. O ensaio precisa ter algum elemento de originalidade, associado ao ineditismo. Assim, precisa ter algo incomum, nunca visto, publicado ou impresso. (MENEGHETTI, 2011, p. 323). 
Pela via da originalidade e do inédito como evidenciado, delineou-se a construção textual que segue, a qual primou por discutir o conceito da modelagem computacional e sua aplicação na educação infantil, assim como suas nuances pedagógicas, com intuito de constituir uma seara tridimensional de manipulação e provocação, sustentada pela argumentação discursiva, visando à consumação dos preceitos alinhados, na convergência da modelagem computacional aplicada à educação infantil, tecendo ponderações ensaístas.

\section{Conceituando ciências cognitivas, tecnologias educacionais e modelagem computacional e seus entrelaçamentos com o processo ensino-aprendizagem}

De acordo com Carvalho (2012, p. 5), as Ciências Cognitivas são um domínio interdisciplinar onde congregam as diversas áreas do conhecimento; têm sua composição inspirada em teorias como cognitivismo, conexionismo, dinamicismo, primando por obter a compreensão acurada dos processos cognitivos e do pensamento cognitivo, enquanto estruturas da mente e aparato da ciência. Esta compreensão acurada da cognição possibilita o estabelecimento do paralelismo "Homem/Máquina: cognição/computação, processos cognitivos/processamento de dados, Software-Hardware/Mente-Corpo".

Assim, as Ciências Cognitivas enquanto dimensão investigativa e metodológica focalizam a empiria, via observação, testagem e experimentação. Dedicam-se a uma aproximação constante da tecnologia e da modelagem computacional, que permite a construção do modelo, simulações ilimitadas e análises inúmeras no campo formativo e da educação.

As tecnologias educacionais podem ser entendidas enquanto um conjunto de técnicas, processos e métodos que estão a serviço da educação e da aprendizagem, promovendo mais desenvolvimento humano, sócio-educativo e melhor acesso à informação e em última instância ao conhecimento.

No cenário das tecnologias educacionais da contemporaneidade registram-se as TICs, as quais podem ser entendidas como um conjunto de recursos tecnológicos integrados entre si, que têm como ferramenta de centralidade o computador, que proporcionam, por meio das funções de hardware, software e telecomunicações, a automação e a comunicação dos processos da pesquisa científica e de ensino-aprendizagem. 
A interlocução homem-máquina, no universo das TICs, associada ao campo da educação, ganha uma dimensão material, palpável e tácita, no campo da realidade virtual e/ou da modelagem computacional.

Para Carvalho (2012, p. 8), via os estudos realizados, a modelagem computacional constitui-se por um processo de abstração do domínio empírico (da experiência) e transposição ao domínio digital, via um sistema multiagente, os quais "são baseados em "agentes", ou seja, unidades de processamento da informação que interagem e moldam o ambiente digital", constituindo a realidade virtual do processo, a qual pode vir a ser capaz de prover o apoderamento do conhecimento.

O termo modelagem computacional, em termos educacionais, é algo recente nas discussões, portanto antes de se abordar sua relação com a especificidade da educação infantil, far-se-á uma explanação do conceito. A modelagem computacional em uma vertente educacional favorece o desenvolvimento do raciocínio, compreensão aprofundada do mundo, apreensão e transmissão da informação, dominância da programação digital, dentre outras aquisições variadas concernentes ao universo do conhecimento interdisciplinar e holístico que o envolve.

A modelagem computacional auxilia e dá suporte à organização de conceitos e elaboração do conhecimento científico. Para Moreira (2014, p. 10), “[...] o termo modelagem computacional, em geral, está associado à computação voltada para a elaboração de simulações computacionais de problemas complexos oriundos das mais diversas áreas do conhecimento". Quando se aborda a modelagem computacional no ensino-aprendizado de conteúdos em uma área do conhecimento, esta diz respeito a uma versão realizada no âmbito computacional, representando um modelo didático-pedagógico.

\begin{abstract}
A criação de modelos de madeira, papel, metal e recentemente de expressões matemáticas tem se desenvolvido ao longo da história e colaborado para a compreensão, a explicação e a previsão dos fenômenos estudados. Os computadores têm proporcionado um novo meio para a construção, análise e descrição de modelos. Com a utilização de computadores, os economistas constroem modelos da dinâmica de mercados, os biólogos constroem modelos de divisão celular, historiadores constroem modelos de civilizações antigas, estudiosos da linguagem constroem modelos sobre a aprendizagem de conteúdos léxicos e de uma gramática, educadores tornam o conteúdo de suas aulas mais atraentes, etc (CARVALHO, 2012, p. 9).
\end{abstract}

Os modelos dão suporte e materializam, como explica a autora, a ideias e conceitos, o que propicia um melhor entendimento destes, em especial na escola. Nesse sentido, a tecnologia é uma ferramenta que facilita essa materialização de modelos na atualidade, pois 
[...] há aplicativos computacionais, especialmente os de modelagem, desenvolvidos com base no princípio de que os computadores podem auxiliar os processos de construção do conhecimento, em contraposição à ideia de que são "máquinas de informação", como a maior parte das páginas da web. A ideia básica é que a tecnologia pode reificar os objetos abstratos, ou seja, torná-los reais (VEIT, 2005, p. 3).

$\mathrm{Ou}$ seja, quando professores utilizam-se de aplicativos, softwares, simulações computacionais; estas podem mobilizar a construção do conhecimento, à medida que o professor realize a mediação entre o conhecimento que se quer desenvolver e a participação dos alunos.

Ainda, Veit (2005, p. 3) comenta sobre o campo educacional, e de como percebe o sujeito que aprende com a possibilidade da inserção da modelagem computacional:

Outra característica importante é a possibilidade de trabalhar com diferentes representações de um mesmo modelo computacional, tais como animações, gráficos, diagramas dinâmicos e representações icônicas de processos. Sob o ponto de vista educacional, estas ferramentas costumam apresentar a possibilidade do "aprenderfazendo", na qual o aprendiz constrói seus próprios modelos ou simulações, e o "aprender-explorando", na qual trabalha com criações de outros. De qualquer modo, o aprendiz é um agente ativo na construção do seu conhecimento e é capaz de desenvolver atividades que extrapolam os limites impostos por lápis e papel.

Como explicitado pela autora, a modelagem computacional pode contribuir no processo de ensino-aprendizagem à medida que o aluno possa ter uma participação ativa, não apenas no sentido de explorar algo pronto, mas também, a depender da situação e da possibilidade, de criar.

A modelagem computacional pode enriquecer o ensino, configurando uma interessante ferramenta para o suporte do desenvolvimento cognitivo dos alunos, podendo ser utilizada em qualquer faixa etária e conteúdo disciplinar.

Veit (2005) destaca o ensino de Física como exemplo de que, a modelagem computacional poderia auxiliar na mudança de práticas não apenas voltadas à memorização, mas também ligadas à experimentação por parte dos alunos, por meio de simuladores computacionais que tragam possibilidades de trabalho com conteúdos curriculares. A autora evidencia uma ideia que pode ser aplicada em qualquer nível de ensino e que pode ter contribuições significativas desde que seu planejamento leve em consideração o seu alunado, contribuindo para:

- a construção e exploração de múltiplas representações de um mesmo fenômeno;

- a construção e investigação de situações-problemas;

- o tratamento de problemas mais gerais e atuais;

- a desmitificação da imagem de Física com uma disciplina difícil, onde o mais importante é decorar fórmulas (VEIT, 2005, p. 5). 
Nesse sentido, Veit e Araújo (2005, p. 10) alertam que, para o uso em sala de aula da modelagem computacional é importante que os professores a analisem, de forma reflexiva, enquanto ferramenta. "Cuidados são necessários, é indiscutível, para que o uso do computador não se constitua em mais um obstáculo epistemológico, criando outra realidade a disputar, com o mundo real, a mente do aluno". Ou seja, o uso reflexivo da modelagem computacional exige preparação para o professor, caso contrário, o que seria um auxílio para a ação docente, torna-se um empecilho.

No âmbito do ensino de biologia, Pereira e Sampaio (2008) evidenciam o uso da modelagem computacional utilizando o software Ambiente de Vida Artificial para EnsinoAprendizagem de Ciências (AVITAE), como forma de criação de realidade virtual por meio da criação de vida artificial, formulação de ambientes variados e da interação entre diferentes organismos com necessidades e hábitos programáveis. Os autores pontuam o uso do programa de modelagem enquanto uma forma importante de construção do conhecimento pedagógico, ponderam ainda que, a modelagem e a simulação abrem a possibilidade dos alunos explorarem e ampliarem seus modelos mentais sobre os assuntos estudados.

A modelagem computacional e seus aspectos cognitivos encontram um paralelo na
dinâmica da metodologia científica [...], onde a construção do modelo é o momento
em que o aluno expressa seu modelo mental, especificando os seres e definindo o
cenário que farão parte do seu ambiente de vida artificial; a elaboração de previsões
é o momento em que ele elabora as hipóteses e observações que deseja realizar no
ambiente de vida artificial, de acordo com as regras existentes em seu mapa
conceitual sobre o problema analisado; e a observação experimental é a etapa em
que se realiza o processo de simulação do modelo criado, permitindo obter
resultados que vão confirmar as hipóteses formuladas ou vão estimular a
reconstrução do conhecimento através da formulação de novas regras (reformulação
do modelo) para atingir o resultado esperado. (PEREIRA e SAMPAIO, 2008, p. 54,
grifos dos autores).

Pelo exposto vemos que a utilização do software seguindo as etapas elencadas pelos autores de construção do modelo, elaboração de previsões e observação experimental é extremamente importante para a modelagem computacional, podendo constituir passos de generalização a outros programas educacionais.

Sampaio (2009) destaca que o uso da modelagem computacional, em sala de aula que articulado ao ensino, permite aos sujeitos envolvidos a alfabetização em ciências, exercitar o pensar crítico, a criação e a construção do novo.

A questão da modelagem no ensino pode ser abordada a partir de pelo menos três perspectivas: a construção do conhecimento em Ciências; a explicitação e 
refinamento das representações mentais sobre um conhecimento; e a percepção do mundo a partir de uma visão de dinâmica de sistemas. (SAMPAIO, 2009, p. 5).

Observa-se assim, que, no processo de modelagem computacional, articulada a educação, "importantes habilidades cognitivas tais como abstração, formulação e testagem de hipóteses são trabalhadas" (SAMPAIO, 2009, p. 7), habilidades estas que são de extrema importância à construção do conhecimento ao longo da vida.

Pinho et al (2009) explicitam em seu trabalho, o uso de blocos de montagem LEGO®, batizado de SIMBA - Simulação com Bloquinhos Animados, na graduação e na pósgraduação em Engenharia de Produção, da Universidade Federal de Itajubá, tendo a modelagem computacional enquanto recurso pedagógico importante, articulado em etapas, tais como: construção de modelo conceitual, coleta de dados e construção do modelo computacional, congregando programação computacional e fase de implementação produtiva na profissionalização dos engenheiros da produção, que vivenciam trabalho em equipe de forma dinâmica.

De outro modo, é possível a utilização do Lego, articulado ao ensino e à modelagem computacional, na Educação Básica (Educação Infantil, Ensino Fundamental e Ensino Médio) ou mesmo em âmbitos de Educação Social, um projeto de educação tecnológica da Lego Educational Division, a qual articula manual instrucional e distribuição de maletas Lego aos interessados em engajamento no projeto, o qual conta com etapas: organizar, programar, construir e apresentar.

Tal projeto é desenvolvido em Curitiba-PR, no Hospital Erasto Gaertner, de acordo com Lipinski (2007, p. 4558): “O trabalho com o Lego possibilita ao educando realizar sua iniciação tecnológica, desenvolvendo competências através de ações experimentais com a adequada mediação do educador". Tem-se a modelagem computacional ganhando materialidade na Pedagogia Hospitalar, com crianças internadas na Pediatria, as quais têm a possibilidade de interagir e aprender de forma inovadora em uma ação que articula educação e tecnologia.

Assim sendo, avaliar constantemente o uso das Tecnologias Digitais da Informação e da Comunicação em Educação (TDICE) no cotidiano dos educandos, aprendizes, torna-se fundamental, tendo em vista que não basta disponibilizar os recursos, há que se analisar se o mesmo serve de suporte ao aprendizado e se cumprem o papel de bons mediadores (CARVALHO, 2012). 
Sobre as capacidades mediadoras das tecnologias digitais como as plataformas de modelagem e simulação, estas podem ser avaliadas segundo certos critérios. A validação destes recursos enquanto mediadores no processo de ensino-aprendizagem deve ser constante. Esta avaliação das TDICEs deve abordar por exemplo: a) análise ergonômica do suporte; b) observações de seu uso pelo público para o qual foi concebido; c) análises comparativas de produções entre usuários que utilizaram certa TDICE e usuários que utilizaram tecnologias tradicionais (livros por exemplo); d) estudos de aspectos do próprio usuário como: o uso do suporte; aspectos cognitivos e afetivos [...] (CARVALHO, 2012, p.13)

O autor explicita que, as tecnologias servem para dar suporte ao aprendizado, nos processos de desenvolvimento de conceitos, em uma interação com o aluno, suas ideias e o contexto no qual se utiliza da ferramenta computacional. Nesse viés, percebe-se que o uso das tecnologias, de modo geral, no ensino não podem ser algo unilateral, pronto e acabado; mas que possa ser um espaço de experimentação e participação dos sujeitos aprendentes, sendo fundamental que tal uso seja significativo a estes.

As Ciências Cognitivas, as tecnologias educacionais e a modelagem computacional estão diretamente relacionadas, podendo oferecer contribuições ao processo ensinoaprendizagem nas diversas áreas do conhecimento, desde que exista o apoderamento de sua utilidade e compreensão, por educadores e educandos.

A modelagem computacional na contemporaneidade adquire importância educativa incontestável, no processo ensino-aprendizagem da Educação Básica ao Ensino Superior. Fato este que se busca aprofundar como dimensionamento na educação infantil, com verticalidade à faixa etária de 4 a 6 anos, dando continuidade à discussão sobre modelagem computacional e a aproximação com o trabalho nessa etapa, por meio da utilização de objetos educacionais.

\section{A modelagem computacional e a aproximação com a educação infantil: possibilidade de implementação pedagógica, via objeto educacional blocos lógicos}

A Educação Infantil primeira etapa da Educação Básica âmbito de formação integral da criança em seus aspectos físicos, cognitivos, afetivos e sociais, bem como científicos e tecnológicos, é hoje o espaço-tempo dos nativos digitais, ou seja, das crianças do século XXI, sujeitos de direitos, cujas TICs fazem parte de seu universo de socialização e meio-ambiente. "O desafio da escola é o de potencializar as virtudes técnicas das TIC, colocando-as a serviço de aprendizagens significativas e não-convencionais, mais adequadas às culturas jovens e infantis”. (BELLONI e GOMES, 2008, p. 742).

Em coaduno com as autoras supracitadas, crê-se no poder formador das TICs para com a formação da criança em plenitude, a qual ganha respaldo na ação do professor, mediador do 
processo educativo, estrategista e responsável por criar condições favoráveis e projetos pedagógicos estruturados, intencionais, a fim de garantir a consolidação de aprendizagens múltiplas. Compreende-se que:

[...] o trabalho dos professores continua sendo fundamental e não pode ser substituído pelas máquinas. Porém, é indispensável que eles aprendam a lidar com a maior autonomia das crianças e a aceitar a hipótese da autodidaxia, além de aprender a usar as TIC em suas práticas pedagógicas [...]. Além de favorecer a aprendizagem colaborativa e cooperativa e desenvolver capacidades de autodidaxia, o uso pedagógico do computador estimula a motivação, desperta a curiosidade e favorece a concentração das crianças que, embora muito jovens, muitas vezes já têm experiência lúdica com estas máquinas e, para elas, seu uso na escola é desafiador e estimulante e lhes parece natural. (BELLONI e GOMES, 2008, p. 741-742).

Verifica-se assim, que o uso do computador na escola da infância favorece a apreensão de atividades significativas pelas crianças, além do que prioriza o desenvolvimento de suas habilidades cognitivas, motoras, emocionais e afetivas, tendo na figura do professor um importante aliado. Como se ressaltou anteriormente, o computador pode ser um agente importante para a construção de novas aprendizagens e por intermédio de softwares educativos é possível brincar e aprender, ou, aprender brincando, conforme preconiza Rosa (2010, p. 3):

[...] na educação infantil a criança ainda não domina o processo de leitura e escrita, dessa forma, os recursos multissensoriais disponíveis nos softwares educativos podem contribuir grandemente para o desenvolvimento de habilidades como a percepção visual, o raciocínio lógico e a criatividade importante para o desenvolvimento cognitivo e para a construção de conhecimentos primordiais para séries posteriores. [...] o software educacional deve despertar a curiosidade da criança, incentivar o trabalho cooperativo e interdisciplinar, estimular a reflexão, o raciocínio e a compreensão de conceitos, contemplar aspectos de linguagem e ainda considerar aspectos socioculturais, éticos e pedagógicos. (ROSA, 2010, p. 3)

Verifica-se que as tecnologias podem ser exploradas aliadas a uma área do conhecimento, constituindo-se importantes aliados no desenvolvimento da criança que ainda não domina a leitura e escrita de textos. Assim, neste momento, optou-se por discutir e exemplificar a área da matemática.

Na primeira infância, a matemática tem dimensão intuitiva. Segundo D’Ambrosio (1986, p. 109): "Em todos os vários ramos da Matemática pode-se considerar computadores fornecendo experiências numéricas e visuais com intento de favorecer a intuição". Por este alinhamento a alfabetização matemática na primeira infância poderá respaldar-se no uso das TICs.

A matemática constitui-se em um dos eixos da educação infantil, proposto pelos Referenciais Curriculares Nacionais (1998): 


\begin{abstract}
As noções matemáticas (contagem, relações quantitativas e espaciais etc.) são construídas pelas crianças a partir das experiências proporcionadas pelas interações com o meio, pelo intercâmbio com outras pessoas que possuem interesses, conhecimentos e necessidades que podem ser compartilhados. As crianças têm e podem ter várias experiências com o universo matemático e outros que lhes permitem fazer descobertas, tecer relações, organizar o pensamento, o raciocínio lógico, situar-se e localizar-se espacialmente (BRASIL, 1998, p. 213).
\end{abstract}

As experiências citadas envolvem a utilização de materiais diversos na sala de aula, como também jogos com conceitos matemáticos, contação de histórias, situações-problemas; o que pode levar as crianças à troca de informações, diálogos, proposições de soluções, com a mediação do professor que ampara tais interações, no intuito de verificar se há uma aproximação com os conceitos a serem desenvolvidos.

Em geral, as propostas voltadas à matemática na educação infantil necessitam envolver a problematização, o que conduz ao desenvolvimento do raciocínio lógico da criança, sempre partindo de situações que envolvam seu cotidiano, para então chegar a atividades mais abstratas. Desse modo, as ações necessitam recriar, "[...] em contextos significativos para as crianças, relações quantitativas, medidas, formas e orientações espaço temporais" (BRASIL, 2010, p. 25-26).

A exploração dos blocos lógicos e seus atributos, por sua vez, remetem à geometria, que enquanto parte integrante do currículo escolar pode ser explorada desde a educação infantil.

\footnotetext{
O pensamento geométrico compreende as relações e representações espaciais que as crianças desenvolvem, desde muito pequenas, inicialmente, pela exploração sensorial dos objetos, das ações e deslocamentos que realizam no meio ambiente, da resolução de problemas. Cada criança constrói um modo particular de conceber o espaço por meio das suas percepções, do contato com a realidade e das soluções que encontra para os problemas (BRASIL, 1998, p. 229).
}

Nessa perspectiva, o desenvolvimento dos conteúdos geométricos relacionados às formas, os blocos lógicos constitui-se um material didático-pedagógico que as crianças podem manipular, observar, comparar e classificar por atributos das peças; e nesse contexto de exploração do material, o professor dialoga, questiona e realiza as mediações entre as concepções das crianças e o que propõe em termos de saberes curriculares.

Os blocos lógicos, manipuláveis e concretos, foram criados na década de 1950 pelo matemático húngaro, Zoltan Dienes, com a intenção de possibilitar o desenvolvimento de relações lógicas pelas crianças, em especial pela exploração dos atributos: grandeza, espessura, cor e forma. (CARDOSO et al, 2010). De modo geral, os blocos lógicos são 
compostos por 48 peças, nas cores primárias (azul, amarelo e vermelho), com quatro formas (quadrado, círculo, triângulo e retângulo), dois tamanhos (pequeno e grande), duas espessuras (fina e grossa), confeccionados em madeira ou espuma vinílica acetinada (conhecida como borracha EVA), e é bastante comum nas instituições de educação infantil e anos iniciais do ensino fundamental.

Figura 1: Blocos lógicos em madeira

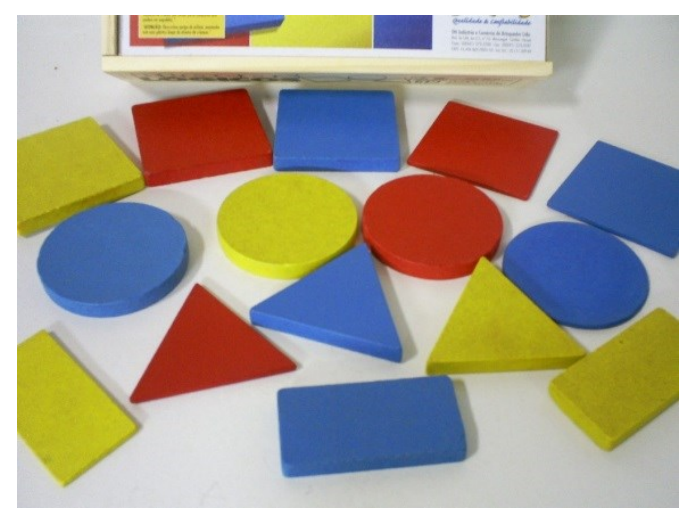

Figura 2: Blocos lógicos em EVA

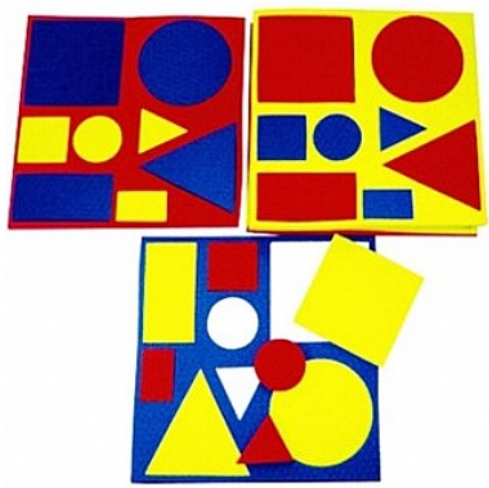

Fonte: www.google.com.br

A utilização desse material pode contribuir para que crianças, desde a educação infantil, exercitem o pensamento lógico de acordo com as especificidades cognitivas de cada faixa etária. Simons (2009) em sua obra evidencia 150 exercícios lúdicos a partir de blocos lógicos para formar o raciocínio lógico, que podem vir a ser utilizados na educação matemática de aprendizes.

O trabalho com blocos lógicos permite que as crianças desenvolvam um raciocínio lógico, [...] bem como o sentido espacial, nomeadamente pela exploração das suas peças e das respectivas propriedades. Este material pode constituir, assim, uma base fundamental para o trabalho em matemática com as crianças, facilitando no futuro o desenvolvimento de diferentes conceitos relativos à Geometria (HONÓRIO et al, 2011, p. 181).

O material manipulável em si não garante a aprendizagem, mas a impulsiona. Honório et al (2011) propõe ações a partir da utilização dos blocos lógicos com crianças de 5 anos. Em um primeiro momento é importante que as mesmas conheçam bem o material, o explorem, antes de uma atividade mais orientada. Após esse momento, podem construir figuras e criar sequências, utilizando os blocos lógicos; sendo que, poderão representar por meio do desenho as figuras que elaboraram.

Salienta-se que, à medida que as crianças já conhecem o material manipulável e o utilizaram como na atividade exemplificada, podem fazer uso de softwares que lhes 
possibilitem analisar e utilizar os blocos lógicos no computador. Contudo, cabe ao professor incentivar a participação dessas crianças, percebendo suas dificuldades e percepções, podendo assim, intervir e mediar qualquer dúvida.

Outrossim, ao se trabalhar com os blocos lógicos, torna-se importante a concepção de que as peças do conjunto são representações de sólidos geométricos, ou seja, objetos tridimensionais. O que deve ficar claro é que as faces dos blocos é que representam quadrados, retângulos, triângulos e círculos, e, essas figuras são bidimensionais (CARDOSO et al, 2010).

Sobre o fato ressaltado por Cardoso et al (2010), é importante que o professor tenha clareza sobre o conceito a ser explicitado para as crianças, pois se a mesma aprende um conceito de maneira equivocada, torna-se difícil romper com esse obstáculo na aprendizagem geométrica, na passagem do plano concreto dos blocos lógicos, a uma atividade de desenho e planificação, ou ao software blocos lógicos, o atributo espessura não toma corpus da ação ou do programa.

Ao se utilizar um software sobre blocos lógicos, o professor necessita antes conhecê-lo para que, ao realizar as atividades com as crianças utilizando a ferramenta, possa interagir e explorar os atributos das peças que aparecem em cada etapa. O software, a atividade no computador não resolve por si só a aprendizagem, mas auxilia no desenvolvimento de conceitos e aplicabilidade destes.

$\mathrm{O}$ educador deve, em determinados momentos, propor às crianças, de um modo intencional, tarefas desafiadoras e de natureza diversificada que potenciem o envolvimento das crianças na sua exploração e discussão, contribuindo para o desenvolvimento dos seus conhecimentos e das suas capacidades (HONÓRIO et al., 2011, p. 198).

Ao refletir-se acerca da implementação da modelagem computacional na educação infantil um âmbito interessante é a exploração do Banco Internacional de Objetos Educacionais, do Ministério da Educação (MEC), anteparo composto por Objetos Educacionais (OE) ou também colocado como Objetos de Aprendizagem (OA) (MATHIAS; VASCONCELOS; FAGAN, 2009), jogos, softwares e programas, os quais visam despertar novos estímulos e desabrochar aprendizagens diversas, ao aproximar o mundo real e o virtual, criando um espaço propício à interatividade, mobilizando iniciativa entre professores e alunos, bem como o desenvolvimento da criatividade. 
O software "Blocs Lógics", criado por Miren Garralda Alonso, disponível no Banco Internacional de Objetos Educacionais do Ministério da Educação (MEC) ${ }^{1}$, é uma opção interessante, a qual é evidenciada em sua interface modelagem computacional na educação infantil, bem como aprofundamento da área da matemática nesta etapa educacional pelo uso dos blocos lógicos.

O software traz os blocos lógicos sendo explorado pelos atributos: cores, tamanhos e formas. Em cada etapa do software há a exploração de um atributo, o qual a criança necessita compreender o que se está solicitando para realizar as devidas relações entre a legenda e a peça correta. O objetivo central é desenvolver o raciocínio lógico dos usuários/alunos, bem como as formas geométricas. Em todas as telas há, no canto inferior direito, uma contagem dos acertos, erros e do tempo que a criança necessitou para realizar a atividade. Um detalhe interessante é que, mesmo que não se finalize a atividade, pode-se passar para a seguinte, o que pode fazer com que o professor explore de forma conjunta com as crianças todo o material e, depois as mesmas fazem as suas tentativas.

$\mathrm{Na}$ figura 3, está evidenciado o trabalho com as formas dos blocos lógicos. Para a execução, a criança clica na forma abaixo, a qual está sem a cor, e arrasta o mouse até a forma correspondente. No caso de acerto, a forma é ocultada, ficando o espaço sem a mesma. Em caso de erro, a forma permanece. O mesmo mecanismo de realização da atividade segue na exploração dos atributos: tamanho e cores, como se ilustra com as figuras 4 e 5 :

Figura 3: Atributo formas.

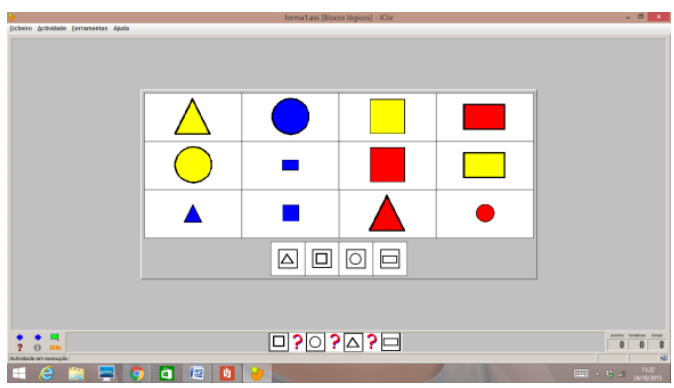

Figura 4: Atributo tamanho.

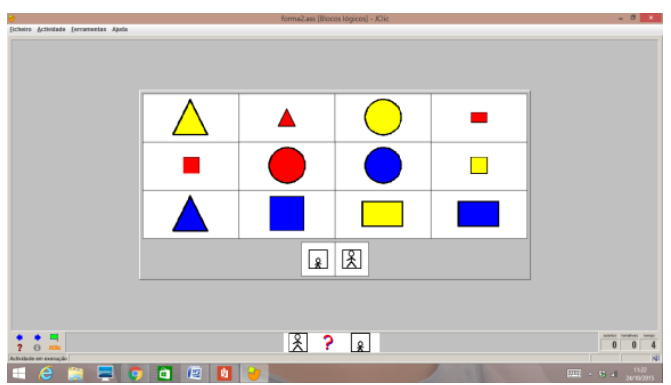

Fonte: Print screan do software blocos lógicos, http://objetoseducacionais2.mec.gov.br/handle/mec/17303.

Figura 5: Atributo cores 


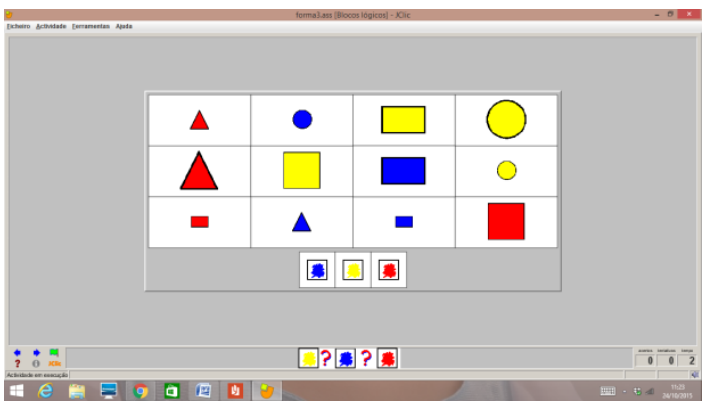

Fonte: Print screan do software blocos lógicos, http://objetoseducacionais2.mec.gov.br/handle/mec/17303.

No módulo seguinte (Figura 6), encontra-se a atividade cuja legenda está relacionada à forma geométrica e ao tamanho (grande e pequena) para que a criança realize a devida relação entre os dois atributos. Nesta atividade, a criança clica sobre a legenda escolhida e, após, sobre a forma. Em caso de acerto a forma desaparece, em caso contrário permanece.

Figura 6: Atributos: forma e tamanho

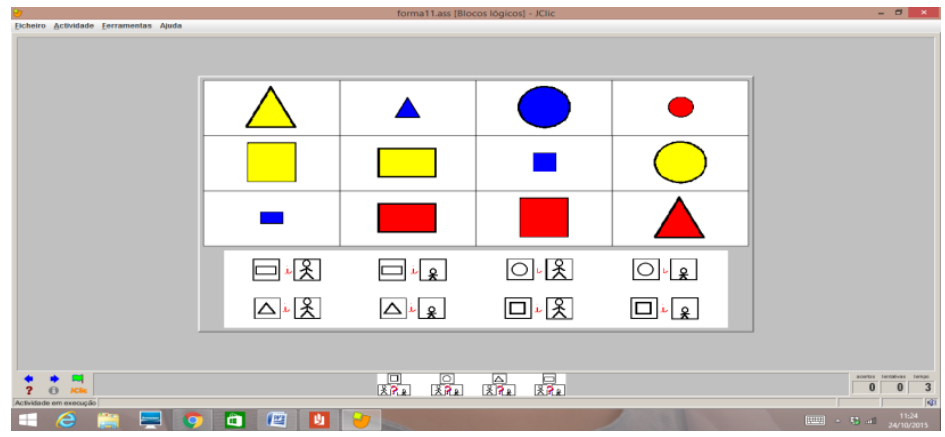

Fonte: Print screan do software blocos lógicos, http://objetoseducacionais2.mec.gov.br/handle/mec/17303.

Em outro módulo, representado pelas figuras 7 e 8 , observa-se que amplia-se a complexidade das relações dos atributos para a realização das atividades. Na figura 7, está o exemplo de que há indicações com as flechas para que a criança escolha a forma e a cor e, no outro a forma e o tamanho. Na figura 8 segue-se o mesmo mecanismo, clica-se sobre a forma escolhida e arrasta-se a mesma até o espaço abaixo a ser preenchido. Em caso de acerto a forma permanece no mesmo.

Figura 7: Atributos forma, tamanho e cor.

Figura 8: Atributos forma, tamanho e cor. 

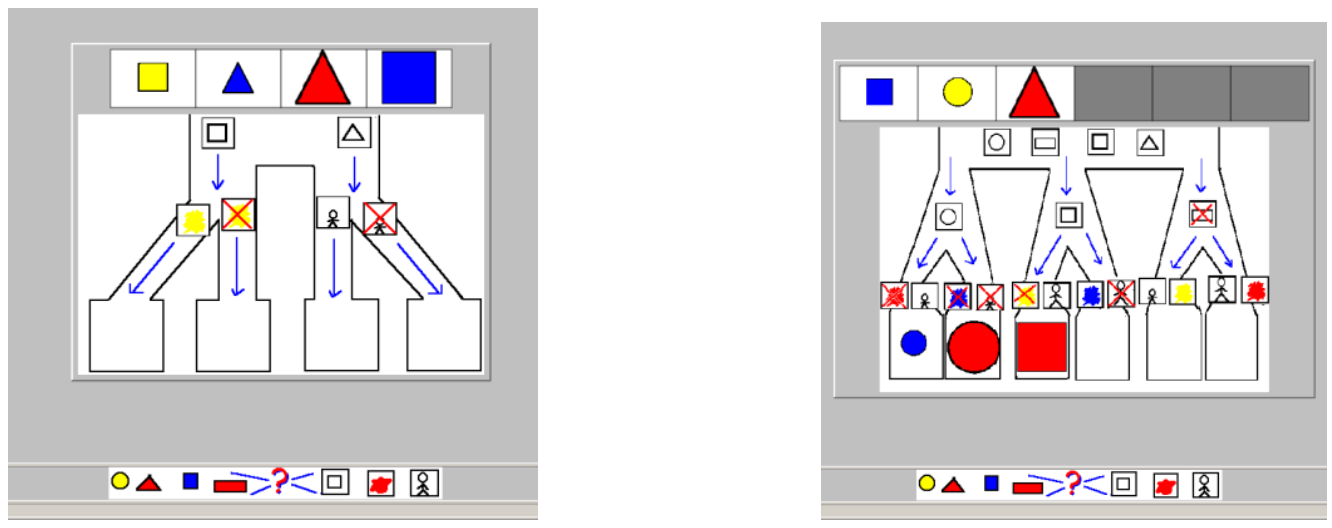

Fonte: Print screan do software blocos lógicos, http://objetoseducacionais2.mec.gov.br/handle/mec/17303.

Outra proposta trabalhada pelo software é de que, em outro módulo, encontra-se a legenda com a forma, tamanho e cor; e acima as formas geométricas. A criança escolhe a legenda e, após clica sobre a forma escolhida. No caso de acerto, aparecem os atributos da forma geométrica escritos por extenso, como por exemplo: "quadrado azul grande", e a mesma desaparece.

Figura 9: Os atributos cor, tamanho e forma e a relação com a escrita

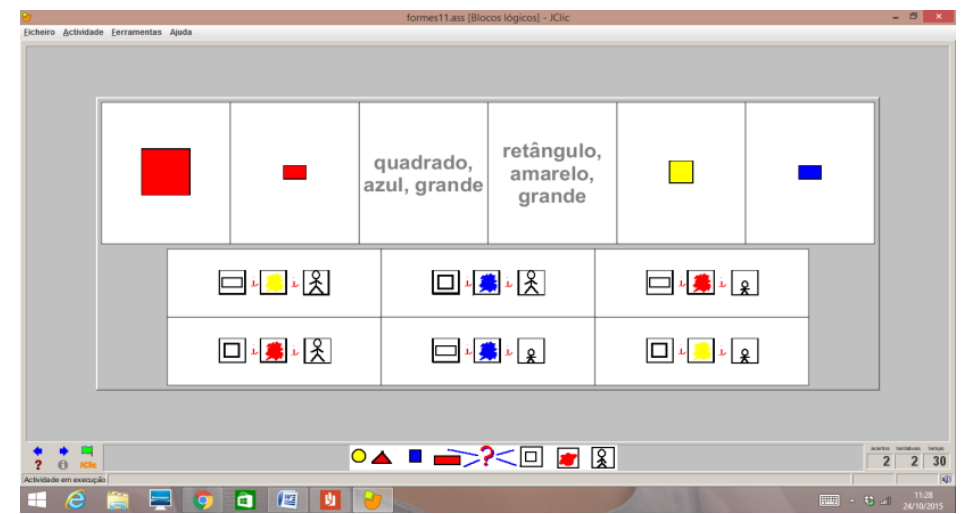

Fonte: Print screan do software blocos lógicos, http://objetoseducacionais2.mec.gov.br/handle/mec/17303.

Estes foram alguns módulos do software sobre blocos lógicos, o qual podem servir de suporte ao aprendizado das crianças no trabalho com material concreto, bem como conceitos de classificação, planificação de sólidos geométricos, relações lógicas e associações.

Para a utilização de materiais manipuláveis (concretos) e de ferramentas (softwares) com o uso do computador, o professor terá que observar os objetivos e estratégias necessárias, portanto, o planejamento é imprescindível para que a modelagem computacional seja utilizada a favor do ensino e, não apenas como ornamento à aula independente do nível de ensino.

O que faz a diferença na sala de aula é a profissionalidade do professor, sua atuação e capacidade de transposição didática. Rosa (2010) é contundente em pontuar que os recursos 
multimídia tornam educadores e educandos parceiros na construção do conhecimento, agentes autônomos e construtores de seu conhecimento, conforme seu ritmo próprio, somando informação, entretenimento e ludicidade.

\section{Considerações finais}

A discussão sobre modelagem matemática desde a educação infantil traz-se reflexões e proposições que podem inovar a prática pedagógica com crianças nesta etapa, as quais estão em contato no seu cotidiano com as tecnologias.

Nesse viés, caberá aos professores buscarem saberes teóricos para que possam problematizar seu planejamento, incluindo conteúdos de uma área específica e softwares que tragam possibilidades de trabalho com objetos educacionais/aprendizagem.

As crianças do século XXI, como dito no texto, são nativos digitais e possuem uma facilidade de exploração nesse ambiente virtual, contudo não se pode deixar de explorar, como no caso dos blocos lógicos para o desenvolvimento de conteúdos matemáticos, o material pedagógico em si, para que após conhecerem isto materialmente possam explorar conceitos via softwares por exemplo.

A discussão teórica proposta e as exemplificações trazidas no texto demonstram que, a área da tecnologia na etapa da educação infantil necessita ser alvo de discussões pelos profissionais da área, bem como estas necessitam estar presentes na formação inicial e continuada de professores.

\section{Referências}

BELLONI, Maria Luiza; GOMES, Nilza Godoy. Infância, Mídias e Aprendizagem: Autodidaxia e Colaboração. In: Educação e Sociedade. Campinas-SP, v. 29, n. 104 Especial, out. 2008, p. 717-746.

BRASIL. Constituição da República Federativa do Brasil. Brasília: Imprensa Oficial, 1988.

BRASIL. Lei de Diretrizes e Bases da Educação Nacional n 9394/96. Brasília: Imprensa Oficial, 1996.

BRASIL. Diretrizes Curriculares Nacionais para a Educação Infantil, Brasília: MEC/CNE, 1998.

BRASIL. Referencial Curricular Nacional para a Ed. Infantil. Vol. 3. Brasília: MEC/SEF, 1998. 
BRASIL. Diretrizes Curriculares Nacionais para a Educação Infantil, Brasília: MEC/CNE, 2010.

CARDOSO, Evelyn Rosana; LOVIS, Karla Aparecida; BARROSO, Mariana Moran; FRANCO, Valdeni Soliani. Blocos lógicos no ensino da Matemática. In: Anais X Encontro Nacional de Educação Matemática: Educação Matemática, Cultura e Diversidade. Salvador-BA, 7 a 9 de Julho de 2010, p. 1-6.

CARVALHO, Leonardo Lana de. Ciências Cognitivas, modelagem computacional e tecnologias educacionais. In: Revista Vozes dos Vales da UFVJM: Publicações Acadêmicas. Viçosa-MG, Brasil, n. 2, ano I,10/2012, p. 1-19.

D'AMBROSIO, Ubiratan. Da realidade à ação: reflexões sobre educação e matemática. São Paulo: Summus, 1986.

HERNÁNDEZ, Fernando. Por que dizemos que somos a favor da Educação se optamos por um caminho que deseduca e excluí? In: SANCHO, Juana Maria; HERNÁNDEZ, Fernando. Tecnologias para transformar a Educação. Porto Alegre-RS: Artmed, 2006, p. 43-62.

HONÓRIO, Claudia Susana Santos et al. A utilização dos blocos lógicos no jardim de infância: uma experiência na formação inicial de educadores. In: GUIMARÃES, Célia Maria; REIS, Pedro Guilherme Rocha dos. Professores e infâncias: estudos e experiências (orgs.). Araraquara-SP: Junqueira \& Marin, 2011, p. 175-200.

LIPINSKI, Neuseli do Rocio Bastos. O Lego na Escolarização Hospitalar. In: Anais VII Educere. Curitiba-PR: PUCPR, 2007, p. 4551-4559.

MATHIAS, Carmem Vieira; VASCONCELOS, Janilse Fernandes Nunes; FAGA, Solange Binotto. Objetos de aprendizagem na educação infantil. In: Novas Tecnologias na Educação. UFRGS, v. 7, no 1, Julho 2009, p. 1-8.

MENEGHETTI. Francis Kanashiro. O que é um Ensaio-Teórico? In: Revista de Administração Contemporânea - RAC. Curitiba-PR, v. 15, n. 2, mar./abr. 2011, p. 320 332.

MOREIRA, Marco Antonio. Modelos científicos, modelos mentais, modelagem computacional e modelagem matemática: aspectos epistemológicos e implicações para o ensino. In: Revista Brasileira de Ensino de Ciência e Tecnologia - RBECT. Ponta GrossaPR: UTFPR, v. 7, n. 2, mai-ago. 2014, p. 1-20.

PEREIRA, André Suppa Thomaz; SAMPAIO, Fábio Ferrentini. AVITAE: desenvolvimento de um ambiente de modelagem computacional para o ensino de biologia. In: Ciências \& Cognição. v. 13, n. 2, 2008, p. 51-70.

PINHO, Alexandre Ferreira de; LEAL, Fabiano; MONTEVECHI, Jose Arnaldo Barra; COSTA, Rafael Florêncio da Silva. Utilização de Lego® para o Ensino dos Conceitos sobre 
Simulação Computacional a Eventos Discretos. In: XXIX Encontro Nacional de Engenharia de Produção. Salvador-BA, Brasil, 2009, p. 1-12.

ROSA, Críssia Passos. O Computador como Ferramenta Pedagógica na Educação Infantil. In: Anais V Congresso de Pesquisa e Inovação da Rede Norte Nordeste de Educação Tecnológica (CONNEPI). Máceio-AL: Secretaria de Educação Profissional e Tecnológica SETEC / MEC e Rede Norte Nordeste de Educação Tecnológica - REDENET, 2010, p. 1-8. Disponível em: http://connepi.ifal.edu.br/ocs/anais/ Acesso em: 20 de outubro de 2015.

SAMPAIO, Fábio Ferrentini. A modelagem dinâmica computacional no processo de ensinoaprendizagem: algumas questões para reflexão. In: Ciência em Tela: rede de investigação, divulgação e educação em ciências. Rio de Janeiro, UFRJ, v. 2, n.1, 2009, p. 1-11.

SIMONS. Ursula Marianne. Blocos Lógicos: 150 exercícios para flexibilizar o raciocínio. 2 ed. Petrópolis-RJ: Vozes, 2009.

VEIT, Eliane Angela. Modelagem computacional no Ensino de Física. In: Anais XVI SNEF. Porto Alegre, 2005. Disponível em: http://www.if.ufrgs.br/cref/ntef/SNEF_RIO/Modelagem_computacional_no_Ensino_de_Fisic a_XVI_SNEF.pdf. Acesso em: 06 de outubro de 2015.

VEIT, Eliane Angela; ARAUJO, Ives Solano. Modelagem computacional no ensino de Física. In: Anais XXIII Encontro de Físicos do Norte e Nordeste. 31/10 a 02/11/2005. Disponível em: $\quad$ http://www.if.ufrgs.br/cref/ntef/producao/modelagem computacional_Maceio.pdf. Acesso em: 06 de outubro de 2015. 